\title{
Failure Analysis of Crankshaft by Finite Element Method-A Review
}

\author{
Ms.Shweta Ambadas Naik \\ Assistant Prof. Mechanical Engineering Department \\ D.Y.Patil Institute of Engg.and Technology,Pune,India
}

\begin{abstract}
The crankshaft is an important and large component of an engine. The function of crankshaft is to converts the reciprocating displacement of the piston into a rotary motion. In this paper, the stress analysis and modal analysis of a 4-cylinder crankshaft are discussed using finite element method. The 3D model of crankshaft was developed in $\mathrm{PRO} / \mathrm{E}$ and imported to ANSYS for strength analysis. In this study, failure analysis of a crankshaft was carried out. Several causes are there to failed the crankshaft. All crankshafts were failed from the same region. Failures had occurred in the first crankpin, the nearest crankpin to the flywheel. Dynamic analysis and finite element modelling were carried out to determine the state of stress in the crankshaft. Finite element analysis was performed to obtain the variation of stress magnitude at critical locations. We know that, the performance of any automobile largely depends on its size and working in dynamic conditions. The design of the crankshaft considers the dynamic loading and the optimization can lead to a shaft diameter that satisfying the requirements of automobile specifications with cost and size effectiveness. The review of existing literature on crankshaft design and optimization is presented. The materials, manufacturing process, failure analysis, design consideration of the crankshaft are reviewed here.
\end{abstract}

Keywords-Stress Analysis, Modal analysis, Fatigue Failure, Optimization, Dynamic Loading, Finite Element Method, Dynamic Analysis

\section{I: INTRODUCTION}

The crankshaft is as shown in fig-1used for conversion between reciprocating motion and motion. In order to do the conversion between two motions, the crankshaft has "crank throws" or "crankpins", additional bearing surfaces whose axis is offset from that of the crank, to which the "big ends" of the connecting rods from each cylinder attach. A crankshaft is as shown in fig-2 consist of main journals, connecting rod journals (crank-pins), counter weight, oil hole and a trust bearing journal. During the service life, ,combustion and inertia forces acting on crankshaft structure, which generally causes the two types of loading-torsional load and bending load. It is connected to a flywheel to reduce the pulsation characteristic of the four-stroke cycle, and sometimes a torsional or vibrational damper at the opposite end, to reduce the torsional vibrations often caused along the length of the crankshaft.

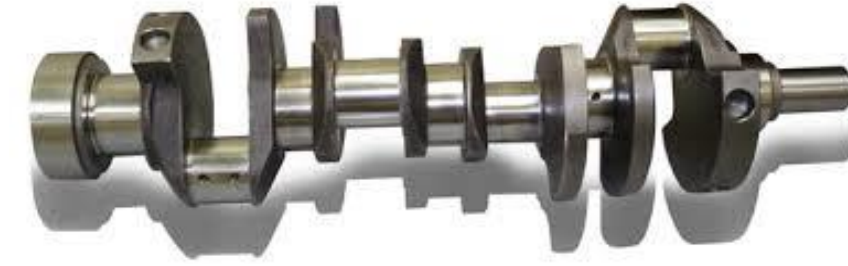

Fig-1 :crankshaft

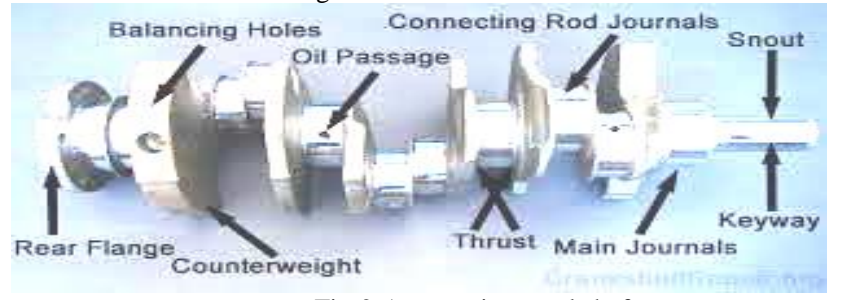

Fig-2:Automotive crankshaft

The crankshaft rotates about its axis, typically with several bearing journals riding on replaceable bearings held in the engine block. As the crankshaft undergoes a great deal of sideways load from each cylinder in a multicylinder engine, it must be supported by several such bearings, not just one at each end. The manufacturing of Crankshafts is done by roll forging from a steel bar or by casting in ductile steel. But forging have certain advantages like lighter weight, more compact dimensions and better inherent dampening, they are commonly used.

The low alloy content makes the material cheaper than high alloy steels. With forged crankshaft, vanadium micro alloyed steels are mostly used as these steels can be air cooled after reaching high strengths without additional heat treatment. Carbon steels are also used, but these require additional heat treatment to reach the desired properties. When the load is lower, Iron crankshafts are today mostly found in cheaper production engines. Some engines also use cast iron crankshafts for low output versions while the more expensive high output version use forged steel. The fatigue strength of crankshafts is usually increased by using a radius at the ends of each main and crankpin bearing. 


\section{MACHINING OF CRANKSHAFT:}

For machining of crankshaft, billet of suitable size is heated to the appropriate forging temperature, typically in the range of $1950-2250^{\circ} \mathrm{F}$, and then pressed into the desired shape by squeezing the billet between pairs of dies under very high pressure. This method of manufacture provides extreme flexibility of design and allows rapid alterations to a design in search of optimal performance characteristics. Steel crankshafts are expensive due to the large amount of material removed with lathes and milling machines, and again the high material cost, and the additional heat treatment required. However, since no expensive tooling is needed, this production method allows small production runs without high costs. A good core may often be easily reconditioned by a crankshaft grinding process. Damaged crankshafts may also be repaired with a welding operation, prior to grinding, that utilizes a submerged arc welding machine.

\section{STRESS ON CRANKSHAFTS}

The various forces acting on the shaft but failure takes place in two positions, bending and twisting. Firstly, failure may occur at the position of maximum bending; this may be at the centre of the crank or at either end. In such a condition the failure is due to bending and the pressure in the cylinder is maximal. Second, the crank may fail due to twisting, so the connecting rod needs to be checked for shear at the position of maximal twisting. The pressure at this position is the maximum pressure, but only a fraction of maximal pressure.

\section{IV:FAILURE OF CRANKSHAFT}

Majority of steel crankshaft failure occurs due to fatigue failure, which may originate at the change of cross-section such as at the lip of oil hole bored in the crankpin. Vibration is one of the cause of failure of crankshaft. If the engine is running with heavy vibration especially torsional vibration, it may lead to crack in the crankpin and journal. One of the reason to fail the crankshaft due to insufficient lubricant. If the lubrication of bearing in the crankshaft is starved, it may lead to wipe out of the bearing and failure of the crankshaft takes place.
Due to extreme pressure, the crankshaft may slip or even bent.Cracks can develop at the fillet between the journal and the web, particularly between the position corresponding to 10 o'clock and 2 o'clock when the piston is at T.D.C.

\section{V: LITERATURE REVIEW}

There is a vast amount of literature related to Finite Element Analysis and optimization of Crankshaft. Many research publications, journals, reference manuals, newspaper articles, handbooks; books are available of national and international editions dealing with basic concepts of FEA. The literature review presented here considers the major development in implementation of FEA.

F.S. Silva(2003)[1] carried out the Analysis of a vehicle crankshaft failure.In this paper investigation was carried out on two damaged crankshafts. They were diesel van crankshafts that were sent to be ground, after a life of about $300,000 \mathrm{~km}$ each. Some journals were damaged on each crankshaft. After grinding, and assembling on the diesel van, the crankshafts lasted about $1000 \mathrm{~km}$ each, and the journals were damaged again. The crankshafts were then sent to be investigated. The cause of the damaged journals was wrong grinding process.Due to that originating small thermal fatigue cracks at the center of the journals, on both crankshafts. These cracks are invisible having sharp edges, acted as knives and therefore originating a very quick damaging of the journal bearings, and as a consequence damaged the journals

For determining the cause of the crankshaft failures, the method involves like-Presentation or formulation of the problem, Visual analysis, Analysis of possible explanations for the problem based on crankshaft failure causes, Definition of laboratory tests. After the analysis of each and every method, and based also on laboratory tests, a conclusion has been drawn. The analysis was separated into three kinds of possible sources for the journal damage:

\section{i) Operating sources}

Operating sources such as oil absence or defective lubrication of journals or high operating oil temperature; or improper use of the engine would be 
enough to damage the journals. The contact between the bearings and the journals would essentially promote a rougher surface of the journals. The heat and stresses during the contact would also eventually promote the propagation of existing cracks, A finer detail of the cracks is shown in fig. 3

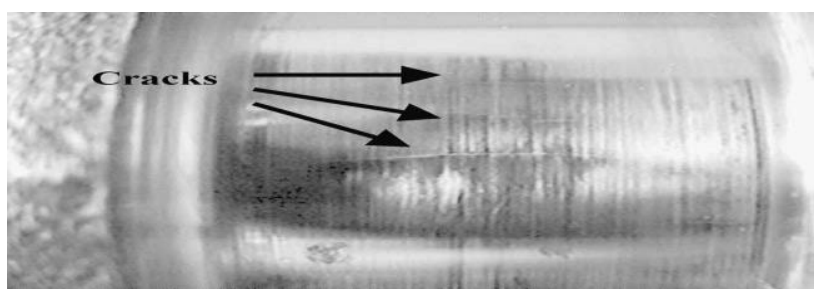

Fig. 3. Finer detail of journal 4 of crankshaft 2.

\section{ii) Mechanical sources-}

Misalignments of the crankshaft on assembly, improperly straightened cranks due to improper repairing, or worn bearings would create a bending moment and higher stresses at the crankshaft. This would also be the effect of vibrations. These higher stresses would originate mechanical fatigue cracks at the weakest points of the crank and the crank would fail by fracture. Fig. 4 shows an example of a train crankshaft that failed due to mechanical fatigue. As can be seen the crack developed at the radius at the geometrical discontinuity.

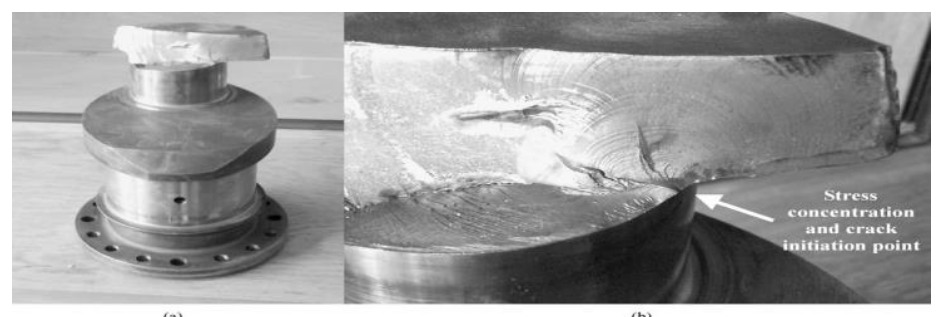

Fig. 4. Train crankshaft failure: (a) part of the crankshaft; (b) mechanical fatigue crack developed at a stress concentration.

\section{iii) Repairing sources:}

It includes misalignments of the journals, misalignments of the crankshaft, high stress concentrations, high surface roughness,improper welding or nitriding; straightening operations; defective grinding. In Grinding Process, The journal rotates with a low rotation speed and the grinding wheel rotates with a high rotation speed. During the grinding process that may cause some small cracks. Defective lubrication may also cause small cracks. Therefore the grinding wheels must be dressed from time to time. If this operation is not observed the wheels may become 'pasted', and this effect will produce poorer cutting characteristics and a higher generation of heat at the contact surface. Again the heat may produce small cracks. The main conclusions of this work as the damage of the journals was originated by the small cracks at the surface of the journals; The small cracks originated by thermal fatigue due to overheating during the grinding operation. This overheating could be caused by excessive depth of cut, or by absence of dressing of the grinding wheels, or by defective lubrication of the grinding operation.

Jaimin Brahmbhatt1, Prof. Abhishek choubey[2] carried out the design and analysis of crankshaft for single cylinder 4-stroke diesel engine. In this paper a dynamic simulation is conducted on a crankshaft from a single cylinder 4- stroke diesel engine.This analysis is done for finding critical location in crankshaft, stress variation over the engine cycle and the effect of torsion and bending load.Von-mises stress is calculated using theoretically and FEA software ANSYS. The relationship between the frequency and the vibration modal is explained by the modal and harmonic analysis of crankshaft using FEA software ANSYS.Fig-5 shows the crankshaft model in ANSYS and Fig-6 shows meshed model of crankshaft. Tetrahedrons element is used for meshing.

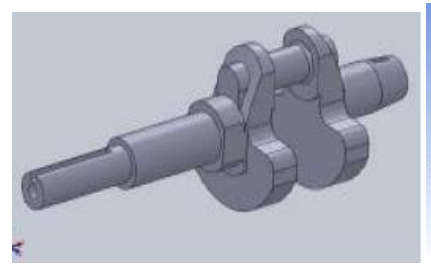

Fig-5 :-Crank Shaft in Ansys

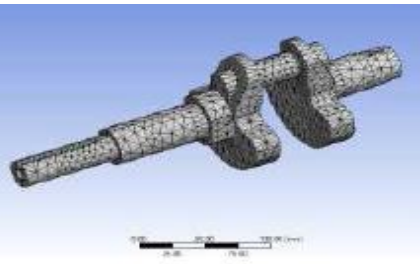

Fig 6:- Meshed model
Define boundary condition for analysis,after applying the Load, Run the analysis.Von mises stresses are calculated and as shown in fig7. Applying the maximum force at phase angle $355^{\circ}$, corresponding Deformation is measured as shown in Fig-8

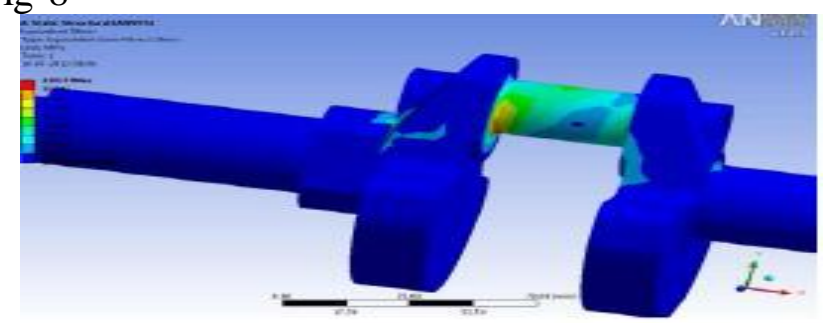

Fig 7: Von misses stress 


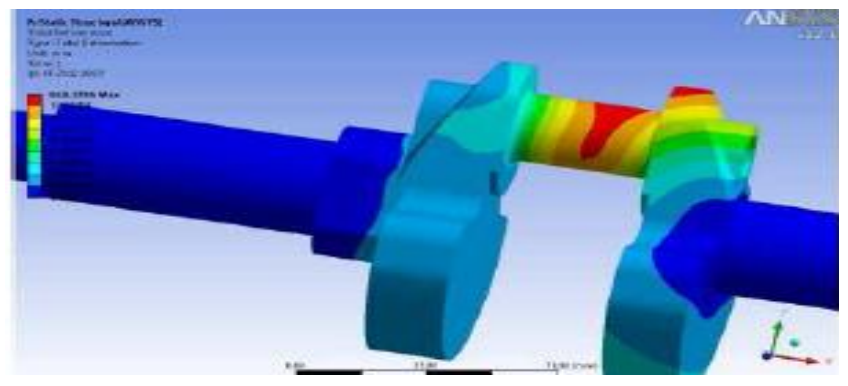

Fig 8 Deformation at a phase angle of $355^{\circ}$

Table:I- FEA results

\begin{tabular}{|c|c|c|c|}
\hline Sr no & Types of stress & Theoretical & FEA Analysis \\
\hline 1 & $\begin{array}{c}\text { Von-Misses } \\
\text { Stresses }\left(\mathrm{N} / \mathrm{mm}^{2}\right)\end{array}$ & 112.25 & 110.3 \\
\hline 2 & $\begin{array}{c}\text { Shear Stresses } \\
\left(\mathrm{N} / \mathrm{mm}^{2}\right)\end{array}$ & 50.15 & 59.89 \\
\hline
\end{tabular}

Above Results Shows that FEA Results matches with the theoretical calculation. From fig- 8 , we can say that the maximum deformation appears at the center of crankpin neck surface. The maximum stress appears at the fillets between the crankshaft journal and crank cheeks and near the central point Journal. The edge of main journal is high stress area. The Value of VonMisses Stresses that comes out from the analysis is less than material yield stress, so our design is safe and we should go for optimization to reduce the material and cost.

Jian Meng,Yongqi Liu, Ruixiang Liu(2011)[3] carried out the work on Finite Element Analysis of 4-Cylinder Diesel Crankshaft. In this paper, The stress analysis and modal analysis of a 4-cylinder crankshaft are discussed using finite element method. Pro/ENGINEER software is used to create 3D model of 480 diesel engine crankshaft and crankthrow as shown in fig-9. The relationship between the frequency and the vibration modal is explained by the modal analysis of crankshaft. The results would provide a valuable theoretical foundation for the optimization and improvement of engine design. The crankpin model was meshed by solid 45 which has 8 nodes tetrahedral feature. Fig 9 shows the meshed model by solid 45. After defining the boundary conditions, the simulation can be started. As the number of elements is large, Pre-Condition CG solver was used here. The results of simulation is given in fig. 11.The maximum deformation is $0.0685 \mathrm{~mm}$ at the most critical loading condition. The maximum deformation appears at the center of crankpin neck surface.

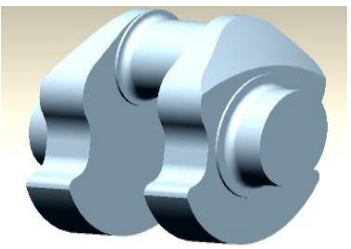

Fig-9: Crankthrow mode

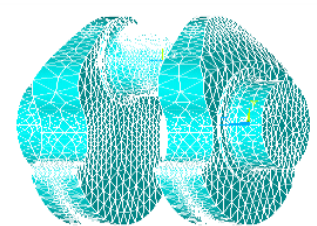

Fig-10:The crankpin finite Element mesh

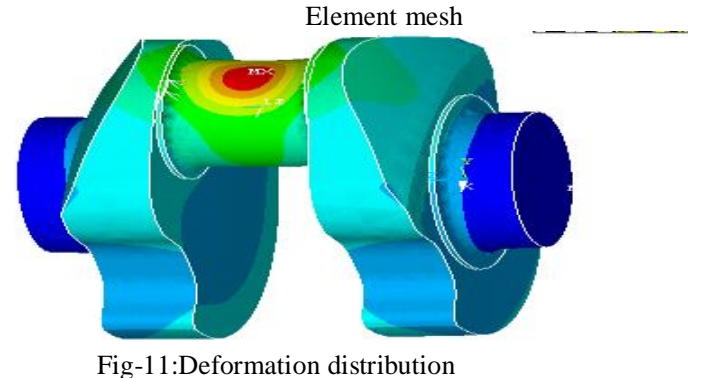

The vibration characteristic of crankshaft was obtained with modal analysis. The values of frequency is as shown in table-II. The maximum deformation of crankshaft appears at the third cylinder, the fourth cylinder and the crankpin between the third and fourth cylinder. As shown from the fig. 12 and fig. 13 , the vibration is bending vibration under the low frequency, and the maximum bending deformation appears at the fillet between main bearing journal and crankpin

Table:II- The first six modal parameters

\begin{tabular}{|c|c|c|c|c|c|c|}
\hline $\begin{array}{c}\text { Modal } \\
\text { orders }\end{array}$ & 1 & 2 & 3 & 4 & 5 & 6 \\
\hline $\begin{array}{c}\text { Frequen } \\
\text { cy } \\
(\mathrm{Hz})\end{array}$ & 116.93 & 124.1 & 234.7 & 316.58 & 344.14 & 354.82 \\
\hline & & & & & \\
&
\end{tabular}

Fig-12: First vibration

modal of crankshaft

Fig-13 : Fourth vibration mode of crankshaft

The maximum deformation appears at the center of crankpin neck surface. The maximum stress appears at the fillets between the crankshaft journal and crank cheeks, and near the central point journal. The edge of main journal is high stress area. The crankshaft deformation was mainly bending deformation under the lower frequency. And the maximum deformation was located at the link between main bearing journal and crankpin and crank cheeks. So this area appear the bending fatigue crack. Base on the results, we can consider the possibility of mutual interference 
between the crankshaft and other parts. The resonance vibration of system can be avoided by appropriate structure design. The results for this study provide a theoretical basis to optimize the design and fatigue life calculation.

Farzin H.Montazersadgh and Ali Fatemi(2007)[4] conducted a study on Dynamic Load and Stress Analysis of a Crankshaft. In this study a dynamic simulation was conducted on a crankshaft from a single cylinder four stroke engine. Finite element analysis was performed to obtain the variation of stress magnitude at critical locations. The dynamic analysis was done analytically and was verified by simulation in ADAMS. The analysis was done for different engine speeds and as a result critical engine speed and critical region on the crankshaft were obtained. Stress variation over the engine cycle and the effect of torsional load in the analysis were investigated. FE analysis were verified by strain gages attached to several locations on the crankshaft. Results achieved from this analysis can be used in fatigue life calculation and optimization of this component. We know that, due to forces applied to the crankshaft cause bending and torsion. Fig 14 shows the variations of bending and torsion loads and the magnitude of the total force applied to the crankshaft. The maximum load which happens at $355^{0}$ is where combustion takes place.

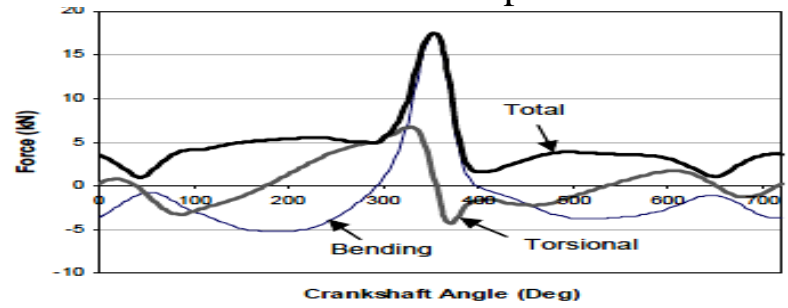

Fig 14: Bending, torsional, and the resultant force at the connecting rod bearing at the engine speed of $3600 \mathrm{rpm}$.

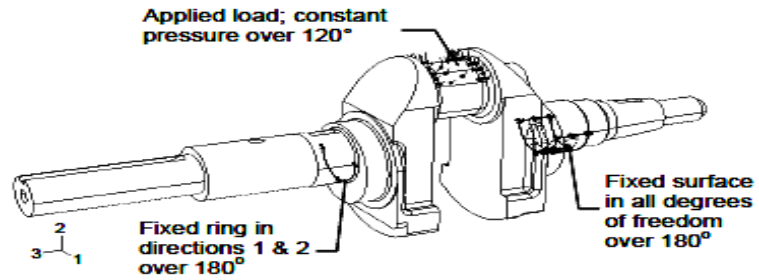

Fig-15:Boundary condition used in a FEA Model

The boundary conditions are shown in Fig15. Boundary conditions rotate with the direction of the load applied. Some locations on the geometry were considered for depicting the stress history.

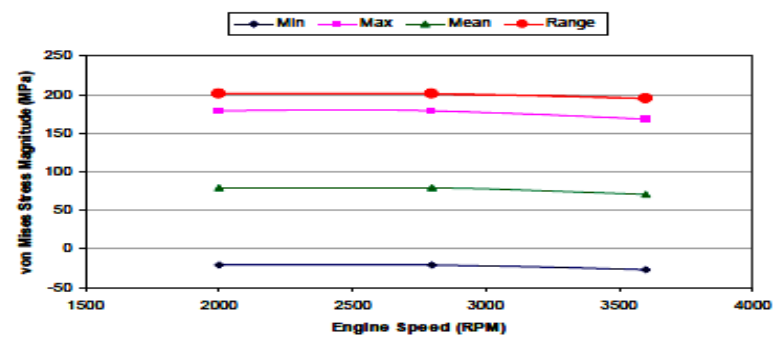

Fig 16: Variation of minimum stress, maximum stress, mean stress, and stress range at location 2 on the crankshaft as a function of engine speed

Fig 16 shows the effect of engine speed on minimum ,maximum, mean and range of stress. This figure indicates the higher the engine speed, the lower the von Mises stress. When the engine speed increases are wear and lubrication. The conclusions from this study is Dynamic loading analysis of the crankshaft results in more realistic stresses whereas static analysis provides an over estimate results. Accurate stresses are critical input to fatigue analysis and optimization of the crankshaft. There are two different load sources in an engine; inertia and combustion. These two load source cause both bending and torsional load on the crankshaft. The maximum load occurs at the crank angle of 355 degrees for this specific engine. At this angle only bending load is applied to the crankshaft. Considering torsional load in the overall dynamic loading conditions has no effect on von mises stress at the critically stressed location. The effect of torsion on the stress range is also relatively small. Therefore, the crankshaft analysis could be simplified to applying only bending load.

G.H. Farrahi, F. Hemmati, S.M. H-Gangaraj, S. Abolhassani, M. Sakhaei (2011)[5] conducted a study on Failure Analysis of a Four Cylinder Diesel Engine Crankshaft Made From Nodular Cast Iron. In this study, The premature breakage in some four cylinder diesel engine crankshafts was reported. All crankshafts were failed from the same region. Failures had occurred in the first crankpin, the nearest crankpin to the flywheel. Dynamic analysis and finite element modeling were carried out to determine the state of stress in the crankshaft. From FEM results observed that the first crankpin fillet is the most vulnerable point to fracture. Soderburg diagram of the studied crankshaft showed that the service operation point, which stands for mean and alternating stresses of the critical region was located in the safe region. Therefore, it can be concluded that fatigue fracture has not occurred in the crankshaft. 
SEM images of the fractured surface also showed cleavage fracture and put in evidence that the failure was brittle fracture. No sign of fatigue failure was observed. The fracture may have been caused by an overload. However, the results suggest re-evaluation of the design and manufacturing. The fillet rolling may play an important role in this study. Optimization of the fillet rolling process by changing process parameters has been recommended to the manufacturer. This recommendation has been adopted by the manufacturer and no further fracture has been reported.The crankshaft was made from GGG 70 ductile cast iron. A broken crankshaft is shown in Fig. 17. The Fractured surface shows a brittle appearance and no Beachmark was observed on the failed region.

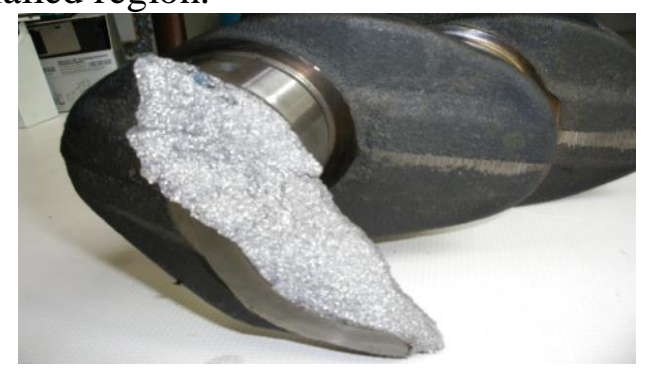

Fig-17: The fractured surface of the crankshaft

Dynamic analysis of a crank and slider can consider the combine effects of combustion pressure and inertia forces. The maximum pressure of $46.2 \mathrm{bar}$ was experienced in the cylinder during combustion. This pressure was exerted on the top of the piston in the dynamic analysis. Since the amount of pressure in suction, exhaustion and compression is very low in comparison with combustion pressure, it can be reasonably neglected in analyses of these three stages. Piston diameter and mass were $88.3 \mathrm{~mm}$ and 505 gr, respectively. A $181 \mathrm{~mm}$, length connecting rod has been connected into both piston and crankshaft. Connecting rod's smaller and bigger hole diameters were $20.948 \mathrm{~mm}$ and $53 \mathrm{~mm}$ respectively. Its mass was considered 740 gr in the dynamic analysis. Engine revolution of 30000 degree per second has been considered as angular velocity of the crank in the dynamic model. Torsional torque that is exerted to crankshaft during its operation was calculated by following equation.

$$
T=\frac{P}{w}
$$

In this equation $\mathrm{P}$ is the power and $\mathrm{w}$ represent the engine revolution. Accordingly, the amount of 128
N.m torque was applied to the extreme surfaces of the crankshaft. Four cases, i.e. combustion in each cylinder, were examined by alteration of the boundary condition in the finite element model. Results found that the most dangerous case has occurred in the first crankpin when the third cylinder was combusted. The equivalent von Mises stress distribution of the whole crankshaft during combustion of third cylinder is shown in Fig. 18. The maximum equivalent stress is $62.7 \mathrm{MPa}$ which is about $15 \%$ of the yield stress of the material.

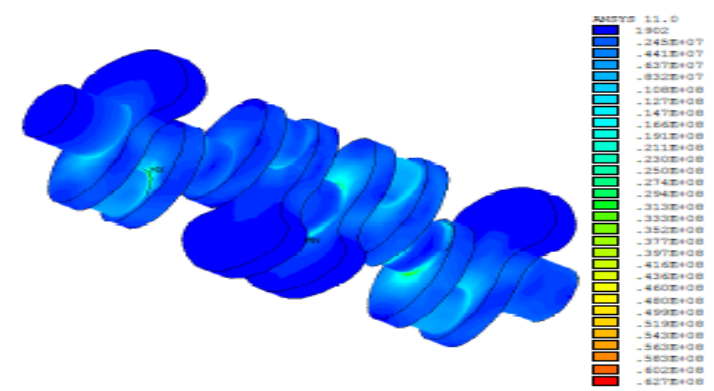

Fig:18 -Equivalent von Mises stress distribution

The conclusion for this study includes, FEM results revealed that the first crankpin fillet is the most vulnerable point to fracture.SEM images of the fractured surface also showed cleavage fracture and put in evidence that the failure was brittle fracture. Based upon results, auther suggest re-evaluation of the design and manufacturing. By changing process parameters, optimization of the fillet rolling process has been recommended to the manufacturer. This recommendation has been adopted by the manufacturer and no further fracture has been reported

Ali KESKİN, Kadir AYDIN (2009)[6] conducted a study on Crack Analysis Of A Gasoline Engine Crankshaft. In this study, failure analysis of a crankshaft was carried out. Nodular graphite cast iron material was used for crankshaft in a gasoline engine. During analysis, it is observed that, the cracks propagated axially on surface of the 4th pin journal. Microscopic observation was conducted on the surface of journals, the main reason of failure was determined as thermal fatigue because of contact of journal and bearing surface. This condition leads to the formation and growth of fatigue cracks. The contact is probably resulted from defective lubrication or high operating oil temperature. In addition to that the contact also caused scratches on surface of the 4th pin journal and 5th main journal. 
In this study, a failed crankshaft reported by automotive service technicians was examined to determine causes of the failure. After the cleaning and visual examination, journals of the crankshaft were cut for failure analysis. The chemical composition of the failed crankshaft material was determined with spectroscopy chemical analysis method with Thermo ARL 3460 test machine. From the visual examination, a crack was determined on the surface of 4 th pin journal. The main crack propagated axially along the surface of the journal from one side to other. There were scratches on surface of the 4th pin and 5th main journals in fig 19 .

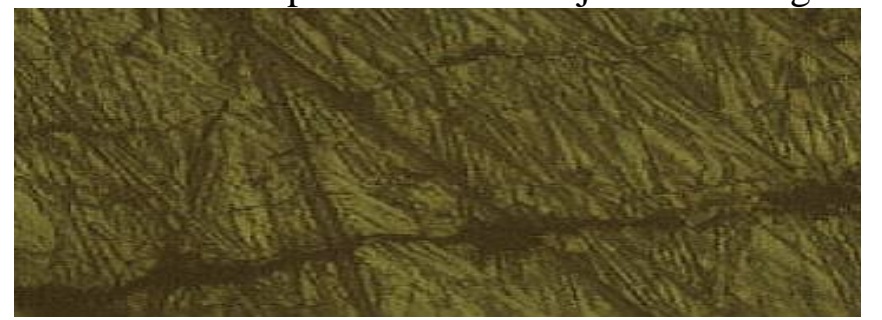

Figure 19. View of the main crack and a micro-crack

Examination showed that the main crack and microcracks were superficial on surface of the journal. A good nodularity of graphite was observed in microstructure of the crankshaft material as shown in fig- 20.

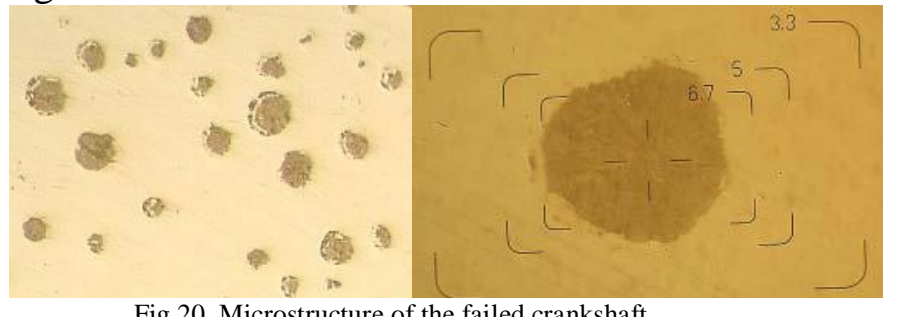

Fig 20. Microstructure of the failed crankshaft

The main reason of the failure was thermal fatigue because of contact of journal and bearing surface. The contact can be resulted from two reasons which are lubricating problems, assembling problems .For the failure analysis, assembling problems can be eliminated because, before the crack problems, the automobile has been driven for long time (58 000 $\mathrm{km})$. In addition, from the lubricating problems, oil absence was eliminated, because automotive service technicians reported that level of the engine oil was suitable during the first examination. Some results were concluded from failure analysis of the crankshaft:Visual examination with microscopy showed that the main crack and micro-cracks propagated axially along surface of the 4th pin journal. In addition, there were scratches on surface of the $4^{\text {th }}$ pin journal and 5 th main journal.
Mechanical properties of the failed crankshaft such as micro-hardness, tensile properties and roughness values were within specified ranged.As a result of this experimental study, the cracks were resulted from thermal fatigue because of contact of journal and bearing surface. The contact can be resulted from defective lubrication or high operating oil temperature.

\section{VI:CONCLUSION}

Above all researchers gives the idea about designing of the Crankshaft. They explained about the various causes of failure of crankshaft and sources of damage the journal also, Most of the researchers used the Pro/E software for the modeling and ANSYS software for analysis. These can be used for designing and analysis of crankshaft in Automobile. In some paper, dynamic simulation is conducted on crankshaft. The stress analysis and modal analysis of crankshaft discussed using FEM. The results would provide a valuable theoretical foundation for the optimization and improvement of engine design.

\section{ACKNOWLEDGMENT}

I sincerely thanks to all the authors who worked on design and analysis of crankshaft and failure of crankshaft.

\section{REFERENCES}

[1] F.S. Silva, "Analysis of a vehicle crankshaft failure," Engineering Failure Analysis 10 (2003) 605-616.

[2] Jaimin Brahmbhatt1, Prof. Abhishek choubey2, " design and analysis of crankshaft for single cylinder 4-stroke diesel engine," International Journal of Advanced Engineering Research and Studies, E-ISSN2249-8974.

[3] Jian Meng, Yongqi Liu, Ruixiang Liu, “Finite Element Analysis of 4Cylinder Diesel Crankshaft, ” MECS,I.J. Image, Graphics and Signal Processing, 2011, 5, 22-29.

[4] Farzin H. Montazersadgh and Ali Fatemi, "Dynamic Load and Stress Analysis of a Crankshaft, ” SAE International, 2007-01-0258.

[5] G.H. Farrahi, F. Hemmati, S.M. H-Gangaraj, S. Abolhassani, M. Sakhaei, "Failure Analysis of a Four Cylinder Diesel Engine Crankshaft Made From Nodular Cast Iron," The Journal of Engine Research/Vol. 22 / Spring 2011.

[6] Ali KESKIN, Kadir AYDIN, "Crack Analysis Of A Gasoline Engine Crankshaft," Gazi University Journal of Science, 23(4):487-492 (2010).

[7] Amit Solanki1, Ketan Tamboli2, M.J.Zinjuwadia3, "Crankshaft Design and Optimization-A Review, " National Conference on Recent Trends in Engineering \& Technology, 2011.

[8] Momin Muhammad Zia Muhammad Idris, “ Crankshaft Strength Analysis Using Finite Element Method," International Journal of Engineering Research and Applications (IJERA) ISSN: 2248-9622, Vol. 3, Issue 1, January -February 2013, pp.1694-1698. 